\title{
EDITORIAL
}

\section{Las lesiones del manguito rotador: ¿contingencia profesional o común?}

\section{Rotator cuff injuries: professional or common contingency?}

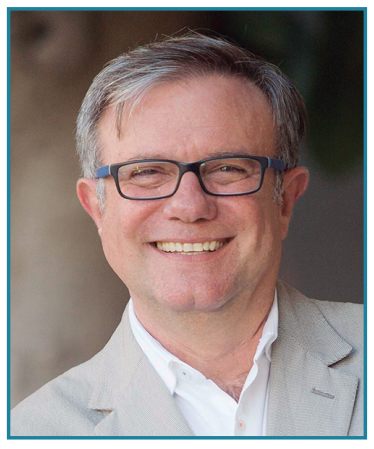

Eduardo Sánchez Alepuz Editor de RETLA

\begin{abstract}
a patología del hombro es la tercera en frecuencia, después de la patología - de la columna y la rodilla, con una prevalencia de entre 70 y 200 casos por 100.000 habitantes. La principal causa de consulta por patología de hombro en una mutua laboral es el dolor y su principal responsable es la patología o enfermedad del manguito rotador. La incidencia de las lesiones de manguito rotador aumenta con la edad, con una afectación en el $25 \%$ de los pacientes mayores de 60 años, pero estas incidencias aumentan cuando analizamos el porcentaje de afectación de lesiones del manguito rotador en determinadas profesiones que requieren esfuerzos repetitivos por encima de la cabeza o profesiones con altas exigencias mecánicas al nivel de los hombros. En estas situaciones se solapan los factores degenerativos que aparecen a partir de los 50-55 años y las altas demandas mecánicas inherentes a determinados tipos de profesiones y trabajos.
\end{abstract}

La enfermedad del manguito rotador se puede considerar una patología grave en el entorno laboral por la cantidad de recursos económicos que se precisan para su manejo conservador, quirúrgico, así como por los largos periodos de incapacidades laborales transitorias (ILT) y las indemnizaciones por secuelas o incapacidades derivadas.

Pero ¿es contingencia profesional toda la patología del manguito rotador que se produce en el entorno laboral?

Según el artículo 156 del Régimen General de la Seguridad Social (RGSS), se considera accidente de trabajo: "Toda lesión corporal que el trabajador sufra con ocasión o por consecuencia del trabajo que ejecute por cuenta ajena".

https://doi.org/10.24129/j.retla.03206.fs2011025

FS $@ 2020$ Sociedad Española de Traumatología Laboral. Publicado por Imaidea Interactiva en FONDOSCIENCE ${ }^{\circledR}$ (www.fondoscience.com). Este es un artículo Open Access bajo la licencia CC BY-NC-ND (www.creativecommons.org/licenses/by-nc-nd/4.0/). 
Esta misma ley, en el apartado 3, dice: "Se presumirá, salvo prueba en contrario, que son constitutivas de accidente de trabajo las lesiones que sufra el trabajador durante el tiempo y en el lugar del trabajo".

Y en el apartado $2 \mathrm{~F}$ de la misma ley dice: "Las enfermedades o defectos, padecidos con anterioridad por el trabajador, que se agraven como consecuencia de la lesión constitutiva del accidente."

Teniendo en cuenta las definiciones del artículo 156 del RGSS sobre accidentes de trabajo, ¿todo dolor de hombro que se produzca en el entorno laboral debe considerarse accidente de trabajo y contingencia profesional?

Existe una información que debemos constatar en la anamnesis de un paciente laboral y es el mecanismo de producción del accidente y las características de la lesión que presenta el paciente, para establecer el nexo causal entre ambas (mecanismo de lesión/tipo de lesión). En general, en la enfermedad del manguito rotador hay 2 hechos que son fundamentales para el inicio de la cascada fisiopatológica de esta enfermedad: los cambios degenerativos por alteraciones vasculares (inherentes a la edad o a patologías sistémicas asociadas) y/o el sobreuso de los tendones del manguito rotador por la actividad fisica (sobrecarga mecánica).

Es evidente que un traumatismo o esfuerzo intenso en el entorno laboral, con resultado de una lesión del manguito rotador, se considerará un accidente laboral, por existir una clara correlación causal y concasual. Pero cuando exista una desproporción entre el mecanismo aducido por el paciente y el resultado manifiesto de la lesión en el hombro con respecto a la clínica, la exploración física y las pruebas de imagen, la relación mecanismo de lesión/tipo de lesión no es tan evidente.

Pongamos un supuesto: "un paciente, tras un esfuerzo menor al tirar de un objeto no muy pesado, presenta dolor, limitación de la movilidad activa y alteración funcional. Tras la exploración física y las pruebas complementarias, presenta una rotura del supraespinoso e infraespinoso con degeneración grasa...". Según la ley 156, ¿debemos considerar este supuesto caso clínico como una contingencia profesional? Es evidente que este paciente presentaba una lesión anterior al mecanismo lesional, aunque según el paciente "nunca" haya tenido ninguna sintomatología. Por tanto, estamos hablando de una lesión crónica que se ha agravado con un mecanismo lesional que no justifica de ninguna manera la lesión (rotura del supraespinoso e infraespinoso, degeneración grasa y signos de cronicidad) que presenta el trabajador. Si aplicamos la ley 156, apartado 2F: "Las enfermedades o defectos, padecidos con anterioridad por el trabajador, que se agraven como consecuencia de la lesión constitutiva del accidente."

Los evaluadores del Instituto Nacional de la Seguridad Social (INSS), basándose en este argumento, estimarán como laboral este supuesto clínico, si el criterio de la mutua discrepa de esta decisión y se deriva al paciente al Servicio Público de Salud (SPS) para su tratamiento, una vez superada la fase aguda del proceso, la mayoría de las veces y a instancia de inspección del INSS, se inicia un expediente para determinar la contingencia del periodo de baja como enfermedad común. En la práctica totalidad de los casos, la resolución concluye que el proceso de ILT iniciado como enfermedad común deriva de un accidente de trabajo (AT) y, por lo tanto, se cataloga como contingencia profesional.

¿Cuál será nuestro argumento legal para sostener que este supuesto no es un accidente laboral? La misma ley 156, en su apartado 4A, dice:

“4. No obstante lo establecido en los apartados anteriores, no tendrán la consideración de accidente de trabajo:

a) Los que sean debidos a fuerza mayor extraña al trabajo, entendiéndose por esta la que sea de tal naturaleza que no guarde relación alguna con el trabajo que se ejecutaba al ocurrir el accidente."

Teniendo en cuenta este apartado de la ley y en el caso que estamos considerando, "paciente con una rotura crónica del manguito rotador con degeneración grasa", no debería ser considerado como accidente laboral, porque el mecanismo lesional no justifica el alcance de la lesión, no existiendo correlación entre el mecanismo de lesión y la lesión del manguito. 
Las concausas anteriores o preexistentes son aquellas que ya existen anteriormente a producirse la lesión; deberían servirnos para determinar entre contingencia profesional o enfermedad común teniendo en cuenta los criterios diagnósticos agudos y crónicos de las lesiones y los mecanismos lesionales.

La realidad es que la ley 156 deja ambigüedades interpretativas para las partes (mutuas laborales/INSS), según como se quieran leer, ver y entender.

Para la correcta interpretación de la ley 156 del RGSS, en lo que a la enfermedad del manguito rotador se refiere, se requeriría un amplio conocimiento no solo de la ley, sino también de la fisiopatología, la etiopatología y la historia natural de la enfermedad del manguito rotador en el entorno laboral, para que las decisiones de una parte (mutua laboral) u otra (INSS) se basasen en principios técnicos y científicos.

Por todas esta razones, en octubre de este año, hemos organizado desde SETLA una interesante webinar sobre: "Manejo de la patología del manguito rotador en el entorno mutual". Si no tuviste oportunidad de verlo, puedes acceder a él en: https://www.setla.es/formacion-online/.

Nuestro objetivo fue intentar poner algo de luz es este complicado mundo de la enfermedad del manguito rotador en el entorno laboral.

Dr. Eduardo Sánchez Alepuz

Servicio de Cirugía Ortopédica y Traumatología (COT). Unión de Mutuas. Valencia Servicio de COT. Hospital IMED. Valencia Editor de RETLA 